\title{
José María Arguedas y la música novoandina: su legado cultural en el siglo XXI
}

José María Arguedas and the New Andean Music: His Cultural Legacy in the $21^{\text {st }}$ Century José María Arguedas e a música novoandina: o seu legado cultural no século XXI

\section{Ulises Juan Zevallos-Aguilar}

THE OHIO STATE UNIVERSITY, ESTADOS UNIDOS

Profesor del Departamento de Español y Portugués, The Ohio State

University, Estados Unidos. PhD en Español, University of

Pittsburgh. Sus últimos libros son Indigenismo y nación: desafíos a

la representación de la subalternidad quechua y aymara en el Boletín

Titikaka (Lima: Instituto Francés de Estudios Andinos/BCR, 2002; 2a. edición 2013), Las provincias contraatacan: regionalismo y anticentralismo en la literatura peruana del siglo XX (Lima: Ediciones del Vicerrectorado de la Universidad Nacional Mayor de San Marcos, 2009) y Movimiento Kloaka: cultura juvenil urbana de la posmodernidad periférica peruana (Lima: Editorial Ojo de agua, 2002). Correo electrónico: zevallos-aguilar.1@osu.edu 


\section{Resumen}

En este artículo se estudia la concepción del escritor peruano José María Arguedas como un héroe cultural peruano. Luego de describir las características de héroe cultural, enfoca su análisis en la producción musical del grupo de fusión rock y huayno Uchpa. Los músicos de este grupo se consideran herederos de Arguedas. Citan su testamento artístico político enunciado de manera sintética en el discurso "No soy un aculturado" (1969) para legitimar su práctica artística y continuar la misión que fue interrumpida por la muerte del autor de Los ríos profundos. Arguedas sostenía la existencia de un individuo quechua moderno que no necesitaba renunciar a su cultura para ser cosmopolita.

Palabras clave: apropiación creativa; héroe cultural; quechua moderno; fusión musical; cosmopolitismo del pobre; nación acorralada; Uchpa; José María Arguedas

\section{Abstract}

This article studies the concept of Peruvian writer José María Arguedas as a Peruvian cultural hero. After describing the characteristic of a cultural hero, we focus our analysis on the musical production of the fusion group rock and huayno Uchpa. The musicians of this group consider themselves heirs of Arguedas. They quote his political-artistic testament, summarized in the speech "I am not acculturated" (1969) to legitimize their artistic practice and continue the mission that was interrupted by the passing away of the author of Los Ríos Profundos. Arguedas talked about the existence of a modern quechua individual who did not need to part ways with his culture in order to be cosmopolitan.

Keywords: creative appropriation; cultural hero; modern quechua; musical fusion; cosmopolitanism of the poor; trapped nation; Uchpa; José María Arguedas

\section{Resumo}

Neste artigo estuda-se a concepção do escritor peruano José María Arguedas como herói cultural peruano. Após descrever as características de herói cultural, foca sua análise na produção musical do grupo de fusão rock e huayno Uchpa. Os músicos deste grupo consideram-se herdeiros de Arguedas. Citam seu testamento artístico político enunciado de maneira sintética no discurso "Não sou um aculturado" (1969) para legitimar sua prática artística e continuar a missão interrupta pela morte do autor de Los ríos profundos. Arguedas sustinha a existência de um indivíduo quechua moderno que não precisa de renunciar a sua cultura para ser cosmopolita.

Palavras-chave: apropriação criativa; herói cultural; quechua moderno; fusão musical; cosmopolitismo do pobre; nação encurralada; Uchpa; José María Arguedas

\section{Cómo citar este artículo:}

Zevallos-Aguilar, Ulises Juan. "José María Arguedas y la música novoandina: su legado cultural en el siglo XXI". Cuadernos de Literatura 20.39 (2016): 254-269. http://dx.doi.org/10.11144/Javeriana.cl20-39.jmam 
LA RECEPCIÓN DE la obra escrita y el conocimiento de la gestión cultural de José María Arguedas (Andahuaylas, 1911 - Lima, 1969) ha sido materia de reflexión de varios especialistas. Para distinguir la lectura de sus obras y el recuerdo de su gestión a favor de los quechuas o mestizos quechuas muchos investigadores han utilizado el concepto de héroe cultural. Por un lado, con el uso de este concepto han querido encontrar la diferencia en la lectura de los libros de Arguedas por estudiantes, intelectuales, críticos literarios y gente común. Por otro lado, han intentado indagar la recepción de su obra y figura por diversos públicos: a) Los analfabetos reales o funcionales que han visto y escuchado la producción audiovisual y actuaciones basadas en la obra literaria de Arguedas y, b) Los testigos y conocedores que recuerdan varias facetas de su vida. Aunque estos intelectuales nunca han definido el concepto de héroe cultural, perteneciente a los estudios del mito, se deduce de sus escritos que José María Arguedas ha sido un héroe cultural para muchos por las siguientes razones. Se constituyó en un representante de la cultura y comunidad quechuas cuando reconoció su parte indígena: "La terca adhesión de Ernesto [alter ego de Arguedas] al universo quechua lo convertía - de alguna forma - en un héroe cultural" (Cornejo Polar 15). Realizó las hazañas de hacer conocer la realidad indígena y de defender sus derechos y reivindicaciones: "[Arguedas es héroe cultural porque] vive no como privilegio sino como tragedia la colonialidad del poder... Arguedas expresó esa condición, y pudo traducir para el mundo dominante una realidad que era absolutamente ignorada, desconocida, negada" (Rochabrún). José María Arguedas tomaba tan en serio su misión que al darse cuenta de que estaba fracasando en sus acciones decidió eliminarse. En otros términos, se ha creado un mito contemporáneo en el cual se recuerda y se toma como modelo la vida y obra de un héroe llamado José María Arguedas: "Arguedas es en el Perú de hoy un héroe cultural, una figura mayor, un ejemplo a seguir" (Montoya, "Todas las sangres" 302). En esta narrativa Arguedas lucha por su comunidad, es portavoz de sus reivindicaciones, se enfrenta a adversarios poderosos, cuando no puede vencerlos, por sus propias limitaciones, deja un testamento artístico y político y decide auto-sacrificarse.

La vigencia y el poder de su mito se comprueba en calles, plazas, parques, promociones escolares y universitarias, conjuntos de música y danza, grupos de teatro que llevan su nombre o el de sus obras. Y también se hace evidente en las conmemoraciones de los 20, 25 años de su muerte, la celebración del centenario de su nacimiento que diversas instituciones peruanas y extranjeras organizaron durante el 2011. Por último, la recuperación o secuestro, dependiendo del punto de vista, de sus restos del cementerio El Ángel de Lima para trasladarlos a la 
ciudad de Andahuaylas, lugar donde Arguedas nació por casualidad y vivió hasta los tres años, demuestra no solo su mitificación sino también su santificación por el catolicismo vernáculo de sus paisanos (Montoya, "Otra tumba para Arguedas"). Sus creyentes consideran a sus huesos como una reliquia con la que hay que estar cerca. Su tumba recibe muchas visitas y es objeto de peregrinaciones en el cementerio de Andahuaylas.

El mismo José María Arguedas contribuyó a la creación de su mito. Es posible que su vida sea la más conocida de todos los escritores e intelectuales peruanos. Cada año salen a luz epistolarios en cuyas cartas Arguedas no tuvo ningún reparo para declarar sus simpatías, amores, odios y rencores. Además, vale recordar que en sus diarios y discurso contenidos en El zorro de arriba y el zorro de abajo (1971) dejó un testamento artístico y político donde asignaba responsabilidades y tareas de manera explícita a aquellos que sabían leer. Su testamento también tenía como destinatario pocos lectores bilingües y biculturales, en castellano y quechua, a fines de los sesenta. Martín Lienhard, entre otros, identificó a este lector y dijo que El zorro de arriba fue escrito para un lector futuro en su estupendo libro Cultura popular andina y forma novelesca: zorros y danzantes en la última novela de Arguedas (1981).

Coincido con aquellas personas que señalan que la obra literaria y pensamiento de José María Arguedas siguen vigentes, puesto que los grandes problemas que afectaban al Perú de su época todavía persisten. Por eso considero que su gestión cultural quedó inconclusa y, por tanto, ha habido lugar para continuarla. Muchas personas ya lo están haciendo. Todos ellos se han declarado explícitamente o han hecho entender que son sus herederos. Su herencia, entendida como misión en este caso, es continuar la lucha por los derechos y reivindicaciones de los desposeídos. A sus herederos se les puede agrupar en letrados y no letrados. En este artículo dejo de lado a los primeros y escojo a los segundos. Las razones de mi enfoque son pragmáticas. Se ha hablado y escrito bastante sobre la obra literaria y hasta tenemos una metacrítica arguediana. Es decir, una crítica de la crítica académica sobre la obra de Arguedas. De otra parte, me atrevo a proponer que los lectores futuros de los que hablaba Lienhard ya existen en gran número. Estos, afortunadamente, no son críticos literarios y tampoco escritores. Ellos son músicos que hicieron escuchar su voz durante y después de la guerra interna que tuvo lugar entre 1980 y 1995 en el Perú.

A estos artistas se les ha agrupado en el movimiento de música novoandina. Dicho movimiento incluye varias propuestas. Entre ellas se puede identificar por lo menos dos tendencias bien definidas. La primera está enfocada en el huayno y apela a una audiencia bilingüe en quechua y castellano que está familiarizada 
con la trayectoria de este género musical de origen precolombino ${ }^{1}$. La segunda ha combinado géneros musicales propios y ajenos. Entre muchos grupos, Uchpa ("cenizas" en castellano) toca grunge, rock y blues con letras en quechua para un público contestatario de diversas generaciones. Dina Páucar y su grupo han creado una fusión de huayno de Ancash y de las alturas de Lima con cumbia y música tecno. Delfín Garay, en un estilo llamado música étnica, ha trabajado piezas musicales utilizando la melodía de canciones de Paul Simon, dando una vuelta de tuerca de la música mundial² ${ }^{2}$ En Europa, el grupo Alborada (Alemania) e Indiógenes (Inglaterra) han inventado un estilo híbrido en el cual mezclan música de la nueva época (New Age), rock, música de los nativos americanos y rap con letras en quechua ${ }^{3}$.

Varios de estos artistas para legitimar su propuesta musical se han declarado herederos de su héroe cultural José María Arguedas ${ }^{4}$. Unos recuperan al Arguedas purista que congelaba a la cultura quechua. Otros al Arguedas que aceptaba el cambio dinámico de la cultura andina y la posibilidad de coexistencia de varias culturas en el mismo territorio de la República del Perú. Se puede discutir interminablemente cuál de los Arguedas es más vigente hoy, en el siglo XXI. Pero la única certeza es que el éxito de sus herederos, en los diferentes circuitos musicales donde se divulga su música, se debe a la difusión y la campaña de sensibilización sobre la música y literatura en quechua que inició el autor de Yawar fiesta en la prensa escrita durante los años cuarenta y cincuenta.

En este artículo, voy a explorar la fusión musical emprendida por el Grupo Uchpa (1993-). Me interesa enfocar las conexiones entre su propuesta musical y el discurso de agradecimiento "No soy un aculturado" que José María Arguedas dio luego de recibir el premio Inca Garcilaso de la Vega en 1968. A este discurso lo considero su testamento artístico político. Contiene puntos claves que a

1 Fredy Roncalla hace un excelente mapeo del huayno contemporáneo en su artículo "El Quechua y la Globalización: el caso del huayno en el youtube. YouTube kanchapi wayllallay ichullay: el huayno quechua en el Internet".

2 Delfín Garay utiliza la melodía de la canción Duncan de Paul Simon para crear la canción Chaskañawichay con letras diferentes a las de Simon. Recuérdese que Paul Simon y Garfunkel se apropiaron de la melodía de "El cóndor pasa" del compositor peruano Daniel Alomía Robles para componer su propia canción. Acabo de publicar un artículo sobre este tema en la Revista de Crítica Literaria Latinoamericana.

3 El creador del grupo Alborada es Sixto Aybar, músico y compositor de huaynos, que nació y creció en el pueblo de Ocobamba, Apurímac.

4 Luego de una rápida indagación encontramos entre sus seguidores al Dúo fosé María Arguedas (Hermanos Julio y Walter Humala), Máximo Damián (el célebre violinista de Ishua), Jaime Guardia y el grupo Alborada. Entre otras actividades artísticas tenemos a los grupos de teatro Yuyachkani y Yawar. 
Arguedas le interesaba resaltar. En este documento el autor de Todas las sangres se define, una vez más, como un "individuo quechua moderno" que, gracias a su propio empeño, los viajes y la ayuda de buenas personas, inicia un proceso cosmopolita de aprendizaje. En una pregunta que le hizo Ariel Dorfman varios años antes, utilizando la dicotomía civilización-barbarie, declaró en el mismo sentido: "entiendo y he asimilado la cultura llamada occidental hasta un grado relativamente alto; admiro a Bach y a Prokofiev, a Shakespeare, Sófocles y Rimbaud, a Camus y Eliot... ¿Qué soy? Un hombre civilizado que no ha dejado de ser, en la médula, un indígena del Perú" (Arguedas, "Conversando con Arguedas" 26). En esta declaración y en otras, sus nuevos conocimientos y viajes no hacen que pierda su cultura, es decir, que se aculture como la antropología de su época pronosticaba. Al contrario, le permite ser bicultural y darse cuenta de la existencia de una "nación acorralada" quechua en el territorio peruano dominada por otra nación de acorraladores con quienes tiene cuidado de no especificar quiénes son para no enemistarse con colegas y amigos. ${ }^{5}$ Sin embargo, reconoce que sus ansias de conocer y viajar cobraron pleno sentido gracias a dos principios: "la teoría socialista" y el darse cuenta de que "el Perú es una fuente infinita de creación" por su diversidad cultural y ecológica. Para Arguedas este documento cobró tanta importancia que pidió a sus albaceas literarios su inclusión como prólogo de El zorro de arriba y el zorro de abajo. Pero estos no cumplieron su deseo. Lo pusieron en una sección que crearon y la publicaron como epílogo. Con esta acción se le restó relevancia al discurso como testamento artístico y político.

5 Esta noción donde nación es sinónimo de cultura ha sido recuperada, entre varios, por Bruce Mannheim. Para Mannheim los quechuas contemporáneos son una "nación acorralada" en dos sentidos. Son objetos de discursos en castellano y su homogeneidad lingüística es el resultado de políticas culturales coloniales y neocoloniales. Otros han hecho una lectura oblicua de tal concepto. Por ejemplo, Juan Carlos Ubilluz considera que los indigenistas y enemigos de los indígenas coinciden en utilizar el "fantasma de la nación cercada" con el propósito de justificar su defensa o ataque. La idea de indígenas aislados, sin contacto con el mundo moderno, ha servido para que los indigenistas los defendieran con una actitud paternalista. Del mismo modo, los anti-indígenas consideran que el autoaislamiento indígena ha hecho que sigan en un estado salvaje y por lo tanto merecen ser explotados o eliminados. Pero la concepción de "nación acorralada" de Arguedas es mucho más sutil y explica las dinámicas de explotación y exclusión en el Perú. El acorralamiento de los quechuas ha sido llevado a cabo por agentes externos (los acorraladores) al impedirles educación formal, libertad de movimiento, acceso a los medios masivos de comunicación en el espacio de la hacienda. Sin embargo, los acorralados han encontrado el camino para superar el cerco. Los quechuas han roto, en muchas ocasiones, el cerco con la decisión de migrar, educarse o rebelarse en contra de sus acorraladores. De esta manera, el término implica interacción de los acorralados con el mundo de afuera y al mismo tiempo está señalando la responsabilidad política y social de acciones nefastas de los acorraladores para conseguir beneficio propio en detrimento de otros. 
Para los que no conocen a este grupo de música fusión es necesaria una breve introducción. Uchpa es la banda peruana más conocida que canta en quechua en ritmos de grunge, blues y rock. Se podría decir que sus actividades empezaron cuando el cantante, Fredy Ortiz, tocaba covers de rock clásico de los 60 y 70 con improvisaciones en quechua en la ciudad de Ayacucho a principios de los noventa. Muchos músicos han integrado la banda en sus distintas configuraciones en Ayacucho y Lima. ${ }^{6}$ El grupo se ha presentado en diversas ciudades peruanas, México, D. F., y La Paz. En el 2014 se encontraba abocado en la producción de su sexto disco de próxima aparición. Uchpa ya ha grabado cinco CD: Qauka Kausay (1994), Wayrapim Kaprichpam (1995), Qukman Muskiy [Respiro diferente] (2000), Lo Mejor De Uchpa (2005) y Concierto (2006). En todas las conformaciones de la banda de Lima, los únicos integrantes estables han sido Fredy Ortiz y Marcos Maizel. Entre ellos existe una fuerte relación simbiótica. Mientras Ortiz escribe las letras de las canciones en quechua, Maizel hace los arreglos musicales.

En sus pronunciamientos y su propuesta musical, Uchpa se ha declarado heredero de Arguedas. En el plano personal la trayectoria vital de Arguedas es un modelo digno de imitar. Fredy Ortiz (1964 Ocobamba-Apurímac) se considera un "individuo quechua moderno", mediador entre varias culturas, migrante, orgulloso de su cultura local y defensor de ella. En este sentido, Ortiz recupera la frase "Yo no soy un aculturado; yo soy un peruano que orgullosamente, como un demonio feliz, habla en cristiano y en indio, es español y quechua" (Arguedas, "No soy un aculturado" 257). Esta frase la ha repetido como mantra en varias de sus presentaciones y la tiene como lema en su cuenta de Facebook. Vale la pena recordar que la frase tan citada y mentada es una primera conclusión de la autorreflexión de José María Arguedas sobre su identidad cultural y sus contribuciones literarias y antropológicas en su discurso "No soy un aculturado". De igual manera, otras ideas planteadas en este discurso pertenecen a una concepción del cambio cultural más flexible. En los años cuarenta Arguedas estaba más cerca

6 La primera banda estuvo integrada por los músicos ayacuchanos Igor Montoya, Tampa, Koki, Mr. Blues, Jaime Pacheco y Fredy Ortiz de Ocobamba. Esta primera agrupación quedó disuelta cuando Fredy Ortiz se mudó a Lima para entrenarse y trabajar como policía. En su mudanza llevó maquetas grabadas en los ensayos de Ayacucho y reorganiza el grupo en la capital con el mismo nombre y con otros integrantes. En Lima la primera banda estuvo constituida por el belga-peruano Bram Willems, en el bajo, y los limeños Marcos Maizel Mesías en primera guitarra, Juan Manuel Alván en guitarras rítmicas, armónica y coros, Ivo Flores en la batería y Fredy Ortiz como cantante principal. Los músicos que tocan los waqrapucus son los primos tocayos Juan Espinoza. El nombre artístico del danzante de tijeras es Chelele. Cuento una historia más extendida del grupo en mi artículo "Uchpa: música novoandina, movimiento y cosmopolitismo quechuas". 
del purismo y la conservación cultural o "la protección de la diferencia cultural" como lo señala Raúl Romero. Muestra de ello es la campaña que hizo en contra de la fusión de Ima Sumac y Alejandro Vivanco en los 40 y 50.

En este discurso Arguedas, alejándose de todo purismo, conservacionismo y proteccionismo cultural y étnico se declaró "un individuo quechua moderno que, gracias a la conciencia que tenía del valor de su cultura, pudo ampliarla y enriquecerla con el conocimiento, la asimilación del arte creado por otros que dispusieron de medios más vastos para expresarse" ("No soy un aculturado" 256). Veinticinco años más tarde Uchpa alcanzó la modernidad con la fusión de varias tradiciones musicales. En este sentido, su fusión musical fue posible previo conocimiento de dos o más tradiciones para mezclar. Se puede hacer una historia del aprendizaje de ellas en el caso de Fredy Ortiz. En varias entrevistas ha declarado que en su primera infancia aprendió a cantar ritmos norteamericanos (gospel y blues) en una iglesia evangélica de Ocobamba. Luego, a partir de los ocho años, empezó a pasar las vacaciones escolares, de enero a marzo, en Andahuaylas donde un tío, que pertenecía a la generación hippie, lo introdujo en el conocimiento de varias tendencias del rock de los 70 .

De otra parte, Fredy Ortiz cantó y bailó las diversas variedades del huayno y el harawi desde su primera infancia en su proceso de socialización. En su lugar de origen, el pueblo de Ocobamba, se habla el quechua chanka. En la región donde se encuentra Ocobamba se baila la danza de las tijeras con su orquesta de arpa y violín andinos y se utiliza el waqrapucu. El waqrapucu es un instrumento hecho con cuernos de toro unidos con tiras de caucho que se toca como acompañamiento de algunas danzas como el carnaval, pero tiene más la función de anunciar, cual cornetas, ceremonias y ritos que van a tener lugar. La integración de la danza de las tijeras en el programa de Uchpa tiene pleno sentido. En la cultura quechua es casi imposible desligar música y baile. El carácter ritual de esta danza que se remonta hasta la época precolombina ha marcado a diferentes generaciones de la región chanka. José María Arguedas tenía especial predilección por la danza de tijeras y su música. Aparte de ser un tema en varias de sus obras literarias, Arguedas contribuyó a su conocimiento y difusión ${ }^{7}$. Algo similar ha ocurrido en la tradición del rock . En otros términos, tanto en el rock como en los conciertos de Uchpa lo que se está haciendo es la fusión de una música

7 He trabajado este tema en el capítulo 3 de mi libro Las provincias contraatacan (91-123).

8 Precisamente grupos como Led Zeppelin y Deep Purple que le gustan a Ortiz incorporaron en su repertorio musical sus tradiciones locales, como la balada celta. Jim Morrison, cantante de The Doors, bailaba con pasos de Pow Wow, vestido con chaleco, pantalones de cuero y un cinturón de metal propios de la vestimenta de los navajo y apaches en sus conciertos. 
contracultural masiva de jóvenes del hemisferio norte y tradiciones musicales de origen subalterno como el blues, de la minoría negra norteamericana, más el harawi y el huayno de los dominados quechuas. Marcos Maizel, primera guitarra de la segunda conformación del grupo, recuerda que la mezcla hecha entre diversos géneros fue factible porque "la música andina y el blues llevan a cabo un bello matrimonio musical: ambos utilizan escalas pentatónicas, lo que hace propicia su fusión. La melancolía serrana y la acidez del rock clásico son las dos partes de un todo musical que interpela al oyente de Uchpa. No solo los acerca a sus raíces culturales (en el caso de los peruanos), sino también los invita a destruir sus prejuicios sobre el quechua y la cosmovisión andina" (Hinojosa 29).

Uchpa ha roto el cerco de la "nación acorralada" de la que hablaba Arguedas. Ha borrado la dicotomía cosmopolita/provinciano al hacer una fusión de géneros musicales de origen extranjero como el grunge, blues y rock con géneros musicales y danzas quechuas (huayno y harawi). Articula un cosmopolitismo de los pobres o un cosmopolitismo desde abajo que fue facilitado por los medios masivos de comunicación. Desde los años cincuenta, gracias al cine, la radio, la televisión e Internet, se ha difundido una cultura común de jóvenes en todo el planeta. En esta cultura se han debilitado las determinaciones económicas, geográficas, sociales y culturales. En ese sentido, en la música de Uchpa se puede reconocer melodías de canciones de grupos de rock pesado de los 70 como Led Zeppelin, Deep Purple, Fethro Tull, Black Sabath y Alice Cooper. También es notoria la influencia de Pink Floyd, Nirvana y conjuntos de heavy metal. En cuanto a los instrumentos musicales, de estos grupos extranjeros adoptó la batería, guitarras eléctricas y bajo. De las tradiciones locales incorporó canciones y bailes quechuas, los instrumentos violín, arpa, waqrapuqu y parte de su vestimenta. Se diferencia de otras bandas de fusión cuando dejó de incorporar instrumentos que caracterizaron a propuestas de fusión con tradiciones musicales andinas. Ya no utilizan el charango, el bombo, la quena y la zampoña que identificaron a los grupos de la nueva canción de los setenta y ochenta como Inti Illimani (1967-), Quilapayun (1965-) y al grupo de rock fusión Los faivas (1962). El grupo tiene conciencia de que está haciendo un acto de apropiación creativa: "Nosotros no rockeamos el ande, andinizamos el rock", señala Marcos Maizel (Hinojosa 29).

Fredy Ortiz suscribe el análisis cultural sobre la exclusión económica, política y social de los quechuas peruanos y la posición de mediador entre la "nación acorralada" y la "nación criolla" que se arrogó José María Arguedas en este discurso. Como mediadores, Uchpa y Arguedas tuvieron que crear un texto intercultural. En el caso de Arguedas, el quechua literario. En el caso de Uchpa, una fusión musical. Así se constituyeron en mediadores entre la cultura 
oprimida quechua y las culturas opresoras en sus versiones occidental y criolla. Por eso Uchpa ha mezclado distintas manifestaciones culturales en su música, letras, instrumentos y vestimentas para conseguir audiencias locales, nacionales e internacionales. En este sentido considero que $U c h p a$ ha dado un paso más en comparación a Arguedas. Ha deconstruído el relato de la autenticidad y las dicotomías local/global, tradición/modernidad. Sobre todo quiero enfatizar que sus conciertos, cobertura periodística, CD y DVD han contribuido al desarrollo de una sensibilidad sobre la existencia de una cultura quechua moderna que Arguedas la recuperaba en su discurso "No soy un aculturado".

Recuérdese que el autor de Los ríos profundos concebía a los quechuas como una:

[...] nación acorralada, aislada para ser mejor y más fácilmente administrada y sobre la cual sólo los acorraladores hablaban mirándola a distancia y con repugnancia o curiosidad. Pero los muros aislantes y opresores no apagan la luz de la razón humana y mucho menos si ella ha tenido siglos de ejercicio; ni apagan, por tanto, las fuentes de amor de donde brota el arte. Dentro del muro aislante y opresor, el pueblo quechua, bastante arcaizado y defendiéndose con el disimulo, seguía concibiendo ideas, creando cantos y mitos. Y bien sabemos que los muros aislantes de las naciones no son nunca completamente aislantes. ("No soy un aculturado" 256)

En esta línea de pensamiento no hay mejor descripción de la situación de los quechuas en los años ochenta y noventa. A pesar de que Ocobamba se encontraba en una zona de emergencia, donde la población era sometida a una campaña de aniquilamiento, Ortiz y otros músicos seguían creando música recurriendo a sus tradiciones locales y extranjeras. Es decir, Ortiz pudo ser cosmopolita en un contexto local. Siguió la dirección trazada por Arguedas. Él está seguro de que la cultura quechua para universalizarse tiene que cambiar. Ortiz considera que es necesario interactuar entre la tradición y la modernidad, entre lo propio y lo extranjero, lo local y lo global. En palabras de la periodista Gaby Joo: "Uchpa considera que es necesario interactuar entre la tradición y la modernidad, entre lo propio y lo extranjero, y que para insertarse en el mundo actual no es necesario esconder nuestro pasado ni negar nuestras raíces sino más bien conjugar nuestra riqueza cultural con el aporte proveniente de otras fuentes" (Joo). En este sentido, para Ortiz el idioma, como el mayor marcador étnico de su condición quechua, debe revitalizarse. Los jóvenes tienen esta responsabilidad. "El futuro del quechua depende de lo que hagamos los jóvenes con él. Al cantar en quechua, nosotros queremos demostrar que no es un idioma muerto, arcaico, sino una 
lengua moderna, que hace ruido, con la que se puede expresar cualquier aspecto de la vida actual", finaliza Fredy Ortiz (Joo).

Los significados del nombre de la banda y de las canciones también ayudan a entender la propuesta artístico-política del grupo. Como cualquier heredero, escoge solo parte de su legado. Así, de la propuesta del "socialismo mágico" que Arguedas dio en este discurso, Fredy Ortiz deja de lado el componente socialista y se queda con lo mágico. Como resultado del adoctrinamiento que recibió en la Escuela de Policía y la Iglesia evangélica y la manipulación mediática de los ochenta, para él comunismo y socialismo son equivalentes a terrorismo. Cuando recuerda los años en los que escogió el nombre de la banda señala que el acorralamiento de los quechuas no era perpetrado solo por los agentes del capitalismo sino también por el comunismo a la cuarta espada de Sendero Luminoso: "Yo era más joven y estaba metido en la honda rockeraza, y también era policía y miraba el entorno, que tenía dos senderos: el sendero verde (policías) y el sendero rojo (terroristas), en el cual al final de estos enfrentamientos siempre quedaba destrucción [para el pueblo quechua] y eso significaba ceniza. Es lo que queda: Uchpa" (Vera Guerrero). En estas declaraciones que ha repetido, en diferentes variaciones, Ortiz se adscribe a la teoría de "entre dos fuegos" del conflicto interno. Es decir, que los quechuas fueron conminados a apoyar o pertenecer a dos fuerzas que recurrían a la violencia armada para alcanzar sus objetivos militares. Pero en cualquier de los dos casos la muerte y la destrucción era su destino ${ }^{9}$. Sin embargo, en esta explicación de la matanza de quechuas, el detalle que se le escapa a Fredy Ortiz es que de las cenizas, cual ave fénix, han renacido para hacer realidad su gestión cultural. De lo mágico, entendido como lo diferente, Ortiz retiene la concepción del ritual quechua en sus presentaciones. Sus conciertos en provincias empiezan con invocaciones a los apus, realiza un atipanakuy (competencia de destrezas performativas) en el escenario con el danzante de las tijeras y obviamente interactúa con el público.

En cuanto al disimulo, como estrategia de sobrevivencia de la cultura quechua que describe Arguedas en su discurso "No soy un aculturado", Fredy Ortiz, en su calidad de quechua, creó una fusión musical en la que denunciaba esta situación contra sus paisanos y ciudadanos pobres en un lenguaje cifrado. En la composición de sus canciones utilizó la diglosia lingüística existente en el Perú a su favor. Podía

9 Existen demasiados testimonios que denuncian que tanto Sendero Luminoso como las Fuerzas Armadas utilizaban a los quechuas como carne de cañón en sus enfrentamientos. Los quechuas iban siempre a la vanguardia, mal armados o sin armas, mientras que los miembros de las Fuerzas Armadas o de Sendero Luminoso iban atrás protegidos por ese escudo humano. 
criticar las políticas de estado en una lengua que no entendían los funcionarios. Al mismo tiempo se aferró a su cultura y a su lengua para sobrevivir los malos tiempos que estaban pasando. En este sentido, propuestas musicales como las de Uchpa, junto a otras, dieron la esperanza de que su mala situación iba a cambiar.

Se puede decir que la propuesta artística de Fredy Ortiz expresa la voz de la sociedad civil frente al conflicto armado que tuvo lugar entre 1980-200o. Desde su posición de guardia civil, Ortiz vio y sintió en carne propia la corrupción del primer gobierno de Alan García. La corrupción gubernamental afectaba a las tropas encargadas de reprimir a los grupos alzados en armas. En sus declaraciones al periodista Ghiovani Hinojosa del diario La república, aclara que en su canción "Ama Sua, Ama Llulla, Ama Quella", por ejemplo, "decía la verdad de lo que ocurrió, denunciaba la corrupción y los abusos de mi institución policial. No quería pasar piola [no quería hacerme el tonto] frente a los sinvergüenzas" (Hinojosa 29). Como quechua, señala constantemente la diglosia peruana. Agradece el reconocimiento que se ha dado a su propuesta. Es consciente de su contribución a la revitalización del runasimi en cuanto ha generado orgullo étnico y respeto a su cultura. Pero es consciente de que si el Estado peruano no diseña una política cultural el quechua va a desaparecer.

El grupo continúa la propuesta arguediana de aculturación voluntaria o, en términos más actuales, apropiación creativa. Se pueden encontrar varios usos de la lengua y cultura quechuas en el repertorio musical de Uchpa. Se puede distinguir la "bluesizacion" o la "rocksización" de huaynos clásicos como es el caso del huayno de chacra "Chachaschay". Otra ruta es la creación de canciones originales en quechua. Ortiz compuso canciones a sus excompañeros de trabajo policías muertos en combate y a los niños huérfanos, y en contra de los responsables de la guerra y sus secuelas. En estas canciones, que se pueden calificar de sociales o de protesta, el runasimi sirve como código secreto para un público quechua hablante. Como se ha mencionado, la canción "Ama Sua, Ama Llulla, Ama Quella" que denuncia la corrupción del primer gobierno de Alan García durante la guerra interna es un ejemplo claro. El tema de la canción "Pitakmi kanki" trata sobre los niños quechuas huérfanos de padre y madre que dejó la guerra interna. Además, ha compuesto canciones amorosas y de otro tipo sobre experiencias que solo se pueden dar en los Andes. Una de ellas es la canción "Añas Blues" que narra una visión de zorrinos en celo que danzan antes de la cópula la canción "Ananao" donde un amante le pide a su amada que lo deje ${ }^{10}$.

10 He dedicado un análisis de las canciones en mi artículo "Los usos de la tradición musical quechua en las canciones de Uchpa". 
En otro párrafo de su discurso Arguedas relata su proceso de conversión en un "individuo quechua moderno". En otros términos, plantea el proceso de cómo insertarse en la modernización capitalista sin dejar de ser quechua. Las acciones para lograrlo son migración, educación y la creación de redes sociales en su nuevo lugar de residencia. Para Arguedas tenían gran importancia las instituciones educativas públicas, los viajes y la generosidad de algunos individuos de los grupos dominantes ${ }^{11}$. La trayectoria personal y artística de Fredy Ortiz replica la de Arguedas. Medio siglo después Ortiz realizó migraciones internas de su lugar de origen a otros pueblos, ciudades y finalmente a Lima por motivos de educación y trabajo. Aunque no se educó en la universidad, Ortiz contó con la colaboración de extranjeros y limeños sensibles y respetuosos de la cultura quechua. Abraham (Bram) Willems, uno de los bajistas de la banda, es un belga al que sus padres trajeron a Andahuaylas de niño. Integró la banda antes de viajar a Bélgica para seguir estudios universitarios. En los últimos años se ha desempeñado como catedrático en el Departamento de Física de la Universidad Nacional Mayor de San Marcos. Marcos Maizel, el compositor y primera guitarra del grupo,junto con la mayoría de los músicos nacieron y crecieron en Lima. Antes de conocer a Ortiz sabían poco o nada sobre la cultura andina (Joo).

Dentro de la historia del rock peruano, el uso del quechua es un gran avance respecto a lo que se hacía anteriormente. Se encuentran los grupos que repetían canciones en inglés. Otros que las traducían al español y cantaban con la misma música. Finalmente vino la creación de canciones propias en español con ritmo rock. En otros términos, se pasaba de la imitación completa, casi fonomímica, a una apropiación creativa o creación a secas. La apropiación del rock y blues de Uchpa ha servido para demostrar que el quechua es una lengua viva, perteneciente a un grupo que tiene la capacidad de apoderarse de géneros musicales subalternos y contraculturales de la metrópoli que era entendidos como signos de modernidad. De esta forma le han dado prestigio a la lengua y orgullo a sus hablantes, en el sentido que suspende las vergüenzas étnica y lingüística al momento de escucharlos en privado o en conciertos.

También se puede decir que $U c h p a$ ha realizado un mestizaje desde abajo, en el sentido que le da Raúl Romero en su estudio de la música y danza del Valle de Mantaro. Antes de hacer la fusión tuvo que desechar y apropiarse de melodías, ritmos, instrumentos y vestimentas locales y extranjeros para consolidar su

11 José María Arguedas fue acogido por varios de sus compañeros de clases altas en la Universidad Nacional Mayor de San Marcos. Luego en la Peña Pancho Fierro conoció a intelectuales y artistas limeños interesados en la diversidad cultural peruana. 
propuesta musical. Por último, se podría decir que parte de los miembros del grupo (Ortiz, el danzante de tijeras, los músicos del waqrapuqu) son quechuas cosmopolitas. Es decir, su música y su performance son manifestaciones de novedosas y complicadas formas de indigenidad en la que juntan marcos discursivos aparentemente diferentes como una forma de reimaginar categorías de pertenencia en el Perú y los significados de la modernidad en sí misma ${ }^{12}$. La pertenencia se da a varios niveles. En un nivel local, pertenecen a la comunidad quechua, por ello utilizan su propia música e idioma. En un nivel nacional, como jóvenes y quechuas son ciudadanos y por tanto tienen derechos que los gobiernos no hacen cumplir. En un nivel global, practican el rock, música de jóvenes disconformes, que se legitima por su calidad musical más que por el mensaje que expresan. En las dicotomías que crea la modernidad para existir, dejan de lado las categorías de identidad y autenticidad asignadas y las expectativas que se tienen sobre ellos. Estos nuevos quechuas se identifican como indígenas, utilizando el mayor marcador étnico en el Perú que es la lengua. Pero con su apropiación del rock y el blues sorprenden a las expectativas que se tenían sobre ellos. Como inmigrantes del campo a la ciudad deberían escuchar y bailar chicha y no rock o blues que están asignados a los pobladores urbanos de las clases medias y acomodadas. También se podría decir que están llevando a cabo una maniobra decolonizadora cuando Fredy Ortiz declara que el quechua le permite expresar sentimientos muy complejos y que a los conciertos de Uchpa asisten no solo jóvenes urbanos que se identifican con los significados contraculturales del rock y blues, sino también sus padres y hasta abuelos. Es decir, le está asignando valores positivos a una lengua y cultura despreciadas en la diglosia peruana. Se añade a esto el hecho de que Uchpa es contratado para animar fiestas privadas de inmigrantes provincianos prósperos y a un circuito alternativo por las mismas razones. En cuanto a la "rocksización" o "bluesización" de huaynos tradicionales que ha hecho Uchpa hay un proceso de desfolklorización. Recuérdese que folklore fue una categoría inventada para dar cuenta de las culturas rurales orales; luego se incluyó a las prácticas culturales con estos orígenes, pero siempre en contraposición a una cultura urbana letrada superior.

Como se ha visto a lo largo de este artículo, Fredy Ortiz y su banda han suscrito los planteamientos del discurso "No soy un aculturado" de José María Arguedas. Este les proporciona todas las justificaciones para legitimar sus trayectorias personales y propuesta musical. Asimismo, la obra y la trayectoria del autor

12 En esta parte del artículo me son muy útiles las reflexiones de Mark Goodale en su trabajo sobre el rap en aymara de la ciudad El Alto, Bolivia. 
de Todas las sangres se constituye en un modelo a seguir. De esa manera se han constituido en dignos continuadores de su héroe cultural que allanó el camino para que pudieran tener mejores oportunidades en una sociedad tan desigual como la peruana.

\section{Obras citadas}

Arguedas, José María. “Conversando con Arguedas". Por Ariel Dorfman. Recopilación de textos sobre fosé María Arguedas. Compilación y prólogo de Juan Larco. La Habana: Casa de las Américas, 1976. Impreso. El zorro de arriba y el zorro de abajo. Ed. Eve-Marie Fell. 2a. edición. Madrid/París/ México/Sao Paulo/Río de Janeiro/Lima: ALLCA XX, 1996. Impreso. "No soy un aculturado". El zorro de arriba y el zorro de abajo. Ed. Eve-Marie Fell. 2a. edición. Madrid/París/México/Sao Paulo/Río de Janeiro/Lima: ALLCA XX, 1996. 256-258. Impreso.

Cornejo Polar, Antonio. "Arguedas una espléndida historia". Fosé María Arguedas: vida y obra. Roland Forgues, et al. Ed. Hildebrando Pérez y Carlos Garayar. [Lima]: Amaru Editores, 1991. 15-32. Impreso.

Goodale, Mark. "Reclaiming modernity: Indigenous cosmopolitanism and the coming of the second revolution in Bolivia". American Ethnologist 33.4 (2006): 634-649. Impreso.

Hinojosa, Ghiovani. "Pioneros quechua". Domingo, revista de La república 29 de noviembre 2009: 28-29. Impreso.

Joo, Gaby. "El quechua suena en rock". Ideele 146 (2002). Web. 15 feb 2012.

Lienhard, Martín. Cultura popular andina y forma novelesca: zorros y danzantes en la última novela de Arguedas. Lima: Tarea/Latinoamericana Editores, 1981. Impreso.

Mannheim, Bruce. "El arado del tiempo: poética quechua y formación nacional". Revista Andina 1 (1999): 15-54. Impreso.

Montoya Rojas, Rodrigo. "Otra tumba para Arguedas". Elogio de la antropología. Lima: Fondo Editorial de la Facultad de Ciencias Sociales UNMSM/Instituto Nacional de Cultura-Cusco, 2005. 481-482. Impreso.

"Todas las sangres: ideal para el futuro del Perú". Elogio de la antropología. Lima: Fondo Editorial de la Facultad de Ciencias Sociales UNMSM/Instituto Nacional de Cultura-Cusco, 2005. 297-330. Impreso.

Rochabrún, Guillermo. "La fatídica Mesa Redonda: Entrevista con Guillermo Rochabrún". Ideele 207 (2011). Web. 15 febrero 2012.

Romero, Raúl R. Debating the past: Music, memory, and identity in the Andes. Londres/ Nueva York: Oxford University Press, 2001. Impreso. 
Roncalla, Fredy. "El Quechua y la Globalización: el caso del huayno en el youtube. YouTube kanchapi wayllallay ichullay: el huayno quechua en el Internet". Hawansuyo. 14 dic 2010. Web. 15 feb 2012.

Ubilluz, Juan Carlos. "El fantasma de la nación cercada". Contra el sueño de los justos: la literatura peruana ante la violencia política. Hibbett, Alexandra, Juan Carlos Ubilluz, y Víctor Vich. Lima: Instituto de Estudios Peruanos, 2009. 19-85. Impreso.

Vera Guerrero, Melissa. "Uchpa Blues". Atoqsaycuchi: Revista Virtual Independiente de Arte y Cultura 1 (2010). Web. 15 febrero 2012.

Zevallos-Aguilar, Ulises Juan. "El cóndor pasa: apropiaciones y reapropiaciones musicales en globalización". Revista de Crítica Literaria Latinoamericana 80 (2014): 73-86. Impreso.

"Los usos de la tradición musical quechua en las canciones de Uchpa". Crónicas urbanas 16 (2011): 63-76. Impreso.

"Uchpa: música novoandina, movimiento y cosmopolitismo quechuas".

Sembrando huellas: Revista Académico-Científica de Educación, Cultura y Sociedad en los Andes 2 (2011): 117-132. Impreso. 